\title{
Sandstone Reservoir Wettability Alteration Due to Water Softening: Impact of Silica Nanoparticles on Sand Production Mechanism
}

\author{
Shoaib Ezzati ${ }^{1}$ iD , Ehsan Khamehchi 1,* iD \\ 1 Department of Petroleum Engineering, Amirkabir University of Technology, Tehran, Iran \\ * Correspondence: khamehchi@aut.ac.ir;
}

Scopus Author ID 26657370700

Received: 12.04.2020; Revised: 8.05.2020; Accepted: 10.05.2020; Published: 13.05.2020

\begin{abstract}
Low salinity water in the oil reservoirs changes the wettability and increases the oil recovery factor. In sandstone reservoirs, the sand production occurs or intensifies with wettability alteration due to low salinity water injection. In any case, sand production should be stopped and there are many ways to prevent sand production. By modifying the composition of low salinity water, it can be adapted to be more compatible with the reservoir rock and formation water, which has the least formation damage. By eliminating magnesium and calcium ions, smart soft water (SSW) is created which is economically suitable for injection into the reservoirs. By stabilizing the nanoparticles in SSW, nanofluids can be prepared which with injection into the sandstones reservoir increase the oil recovery, change the wettability and increase the rock strength .In this present, SSW composition was determined by compatibility testing, and the $\mathrm{SiO}_{2}$ nanoparticle with $1000 \mathrm{ppm}$ concentration was stabilized in SSW. Eight thin sections were oil wetted by using normal heptane solution and different molars of stearic acid and two thin sections were considered as base thin sections to compare the effect of wettability alteration on sand production. Thin sections were immersed in SSW and Nanofluid, the amount of contact angle and sand production were measured in both cases. The amount of sand produced and the contact angle in SSW was higher than the Nanofluid. The silica nanoparticles reduced the contact angle (more water wetting) and by sitting between the sand particles, more than $40 \%$, it reduced sand production.
\end{abstract}

Keywords: Nanoparticles; Sand production; Wettability alteration; Zeta potential; smart soft water $(\mathrm{SSW})$.

(C) 2020 by the authors. This article is an open access article distributed under the terms and conditions of the Creative Commons Attribution (CC BY) license (https://creativecommons.org/licenses/by/4.0/).

\section{Introduction}

Sandstone reservoirs are one of the most important oil reservoirs. In the sandstone reservoirs due to the manner of deposition, during the production of oil and gas, the production of rock components (like sand and fine) was observed. Sand production causes many problems inside the reservoir (reducing permeability), in the wells and operating tools (production pipe and pumps and physical sand prevention corrosion) and at the ground surface (environmental pollution). Sand prevention methods, generally, divided into physical and chemical groups. Physical methods are much more common, but they do not hinder the sand production inside the reservoir and cause formation damage [1]. Chemical methods, such as using resin, can decrease sand production by increasing consolidation, but the major problem with the resin is that it greatly reduces permeability [2]. In the last few years, many studies have been done on 
smart water to increase the oil recovery factor, wettability alteration is the most important advantage of smart water injection in sandstones reservoirs.

Wettability is the tendency of a fluid to spread on a solid surface in the presence of another immiscible fluid [3]. In a porous medium usually, there are two fluids (wet and nonwet), the wet fluid occupies the smallest pores and the non-wet fluid occupies the largest pores [4]. Petroleum reservoirs have been exposed to water for millions of years during deposition and have been exposed to oil for a very long time after secondary oil migration, and it is possible that after deposition of heavy oil particles on the rock, the rock wettability shifts to oil wetting. Oil-wetted reservoirs had a low recovery factor, so it is necessary to change their wettability. One way to change the wettability is the use of water that has a different composition with formation of water. Usually by intelligently change in seawater composition, produced smart water which can change the reservoir wettability [5]. One of the mechanisms for wettability alteration by smart water is as follows :

$$
\begin{aligned}
& \mathrm{Ca}^{2+} \ldots \text { Clay }+\mathrm{H}_{2} \mathrm{O} \leftrightarrow \mathrm{H}^{+} \ldots \text { Clay }+\mathrm{Ca}^{2}++\mathrm{OH}^{-} \\
& \mathrm{R}_{3} \mathrm{NH}^{+} \ldots \text { Clay }+\mathrm{OH}^{-} \leftrightarrow \mathrm{R}_{3} \mathrm{~N}+\mathrm{Clay}+\mathrm{H}_{2} \mathrm{O} \\
& \mathrm{RCOOH} . . \text { Clay }+\mathrm{OH}^{-} \leftrightarrow \text { RCOO}+ \text { Clay }+\mathrm{H}_{2} \mathrm{O}
\end{aligned}
$$

In general, wettability alteration chemically involves the following three steps: In step (1) $\mathrm{pH}$ increased with the exchange of hydroxyl and calcium ions on the clay surface, In step (2) due to alkalization of the environment, the clay mineral reacts with the hydroxyl ion, in step (3) The oil particles are separated from the rock surface and the rock become water wet [6]. Smart water by wettability alteration improves the wetting properties of the reservoirs, Optimizes the fluid flow and enhances recovery factor [7]. Smart water also affects parameters related to fluid flow in porous media such as relative oil permeability and capillary force. Also, with increasing capillary force, the water will occupy the small pore and increase the recovery factor [8]. Nanoparticles can be used to improve the smart water properties.

The use of nanoparticles has become widespread in all industries in recent decades. In the petroleum industry, nanoparticles are also used in various parts. [9] Nano, to improve drilling fluid properties [10] Separate oil-water emulsion [11] Increase bitumen removal [12] Improve injection water properties, reduce surface tension, Changing wettability and increasing oil produced, are used [13-16]. In recent years, many studies have been done on the use of Nanoparticles to prevent fine migration [17-19]. Nanoparticles are also used to prevent sand production in sandstone reservoirs [20]. A study in 2016 showed that the use of UF-nano $\mathrm{SiO}_{2}$ can reduce the amounts of sand production and had a little effect on permeability [21]. The stability of the nanoparticles in smart water for injection into the sandstone reservoirs can also change the wettability and increase the oil recovery factor and increase the reservoir consolidate and reduce the sand production and its related problems [20]. Therefore, in recent years, many studies have been performed on nanoparticles.

The use of smart water in the oil industry is the most common way to increase oil recovery. Some smart water features such as total dissolved solids, the presence of multivalent cation (hardness), oxidizing agents, and reducing corrosion factors such as $\mathrm{H}_{2} \mathrm{~S}$, affect on the EOR [19, 22], so for improving properties of smart water it is necessary to focus on these features. Smart water has the potential to make widespread changes in the sandstone reservoir. By improving the smart water properties we can produce water that can cause more economical changes in the reservoir [23-26]. Produce soft water is one of the methods to improve smart water properties, to soften the water, we need to eliminate divalent ions such as calcium and magnesium. In 2014, a comparison was made between hard water and soft water, the results 
showing that soft water had a higher yield than hard water [28]. Which the best method to produce soft water in a very high volume is the precipitation process. Soft water increases viscosity, increases surfactant adsorption, and increases polymer stability. In general, the use of soft water can both benefit from low salinity and achieve more economical conditions [2728].

The purpose of this study was to investigate the effect of oil wetted wettability on sand production in SSW. This study was performed in the presence and absence of Nano. The compatibility test was used to determine the optimum soft water composition. The silica nanoparticles were selected for the experiment and the zeta potential test was used to determine the optimum concentration of the nanoparticles. In four containers, a normal heptane solution was made with four different molars of stearic acid, in each container, two Thin Sections were immersed. For complete evaluate the sand production, two Base thin sections (no oil wetted) were used. The ten thin sections that required for testing were placed in the contact angle setup and their images were captured and then all thin sections were dried completely and their weights measured. In five containers, $50 \mathrm{cc}$ of SSW were poured, in five other containers 50 cc of Nano-fluid were poured, and then ten thin sections were placed in a container that had the specifications. The amount of contact angle and weight of sand production was measured daily. In the following, we analyze the tests and result.

\section{Materials and Methods}

\subsection{Materials.}

Sand, salt, deionized water, nanoparticles, normal heptane, stearic acid and kerosene were used in this study.

\subsubsection{Minerals.}

According to one of the southern sandstone reservoirs of Iran, plugs with Specified porosity and permeability were made artificially by cement and sand, for made cement and plug mixed and put in special template then put in oven and oven. XRF test was used to determine plugs composition. The mineralogical composition of the rock (plugs) are given in Table 1.

Table 1. Mineralogy of sands from XRF measurements.

\begin{tabular}{l|l|l|l|l|l|l|l|l|l|l|l|l} 
Elements & $\mathrm{SiO}_{2}$ & $\mathrm{Al}_{2} \mathrm{O}_{3}$ & $\mathrm{CaO}$ & $\mathrm{Fe}_{2} \mathrm{O}_{3}$ & $\mathrm{~K}_{2} \mathrm{O}$ & $\mathrm{MgO}$ & $\mathrm{Na}_{2} \mathrm{O}$ & $\mathrm{SO}_{3}$ & $\mathrm{LOI}$ & $\mathrm{Sr}$ & $\mathrm{P}_{2} \mathrm{O}_{5}$ & $\mathrm{MnO}$ \\
\hline Sand $(\%)$ & 78.81 & 8.95 & 2.42 & 0.55 & 3.16 & 0.21 & 1.74 & 1.47 & 2.58 & --- & --- & --- \\
\hline Cement $(\%)$ & 20.73 & 4.12 & 61.91 & 3.25 & 0.078 & 3.26 & 0.35 & 2.39 & 2.49 & 0.07 & 0.08 & 0.21
\end{tabular}

\subsubsection{Brines.}

Three types of water were made from deionized water in the laboratory. The formation water as an example of the Karanj oil field (one of the southern oilfields of Iran) with salinity about 200,000 ppm and the seawater (Persian Gulf) with salinity about 40,000 ppm and soft water that its composition determined with compatibility test, were made in the laboratory. The compatibility test was performed in two steps for the SSW preparation.1- To determine the optimal diluted sea water.2- To determine the optimal soft water. First, we diluted the seawater 1, 5, 10 and 15 times and combined in equal volumes with formation water and placed in a reservoir temperature simulator for 24 hours and plotted its graph according to the amount of sediments, And it was found that ten times diluted water had the lowest sediment with 
formation water, and for continuing the work ten times diluted seawater with salinity about 4000ppm was used. To obtain the SSW composition, the Minitab software and the Taguchi's algorithm were used. In Taguchi's algorithm, two rows and two columns were defined and Table 2 was obtained to determine the composition of the SSW.

In the seawater compounds, the calcium and magnesium ions were removed, the amount of $\mathrm{Na}_{2} \mathrm{SO}_{4}$ was assumed constant and the $\mathrm{KCl}$ was used to compensate the compounds to bring the concentration of SSW to $4000 \mathrm{ppm}$ (10 times diluted seawater). We combined the four compounds obtained in Table 2 in equal volumes with formation water and placed on a magnetic stirrer for 1 hour and then placed in a reservoir temperature simulator for 24 hours. The reason for placing the samples in the oven was to obtain the mass of the sediment resulting from the incompatibility of soft water and formation water. We plotted the diagrams (Fig.1) of all four compositions against the mass of the sediment.

Table 2. Taguchi's algorithm.

\begin{tabular}{l|l|l|l|l|c|c} 
Composition & $\mathrm{C} 1$ & $\mathrm{C} 2$ & $\mathrm{C} 3$ & $\mathrm{C} 4$ & Row equivalent & Column equivalent \\
\hline $\mathrm{A}$ & 1 & 1 & 2 & 2 & $\mathrm{~A} \rightarrow \mathrm{NaCl}$ & $1 \rightarrow 0.25$ \\
\hline $\mathrm{B}$ & 1 & 2 & 1 & 2 & $\mathrm{~B} \rightarrow \mathrm{NaHCO} 3$ & $2 \rightarrow 0.75$
\end{tabular}

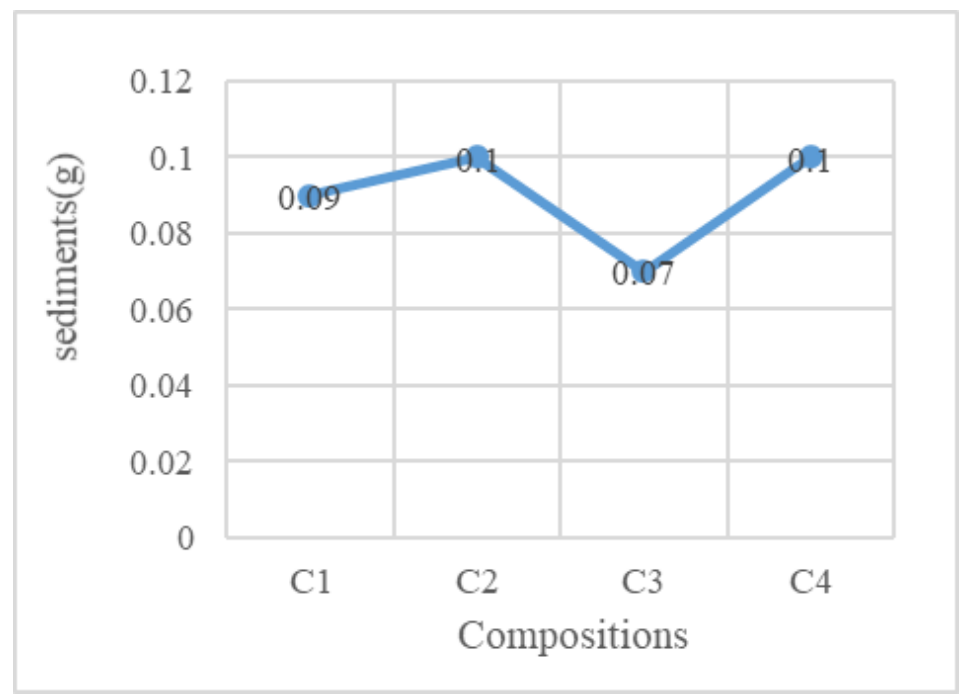

Figure 1. Weight of sediments after $24 \mathrm{~h}$ in $65^{\circ} \mathrm{C}$.

According to Figure 1, composition number 3 had the lowest amount of incompatibility and was used as the optimum water for testing. In Table 3 we can see the compositions of formation water, seawater, diluted seawater, and SSW.

Table 3. Composition of formation water, sea water, diluted water and smart soft water (SSW).

\begin{tabular}{l|c|c|c|c|c}
\multicolumn{1}{c}{ Components } & $\begin{array}{c}\text { Formation water } \\
\text { weight }(\mathrm{g} / \mathrm{l})\end{array}$ & $\begin{array}{c}\text { Sea water } \\
\text { weight }(\mathrm{g} / \mathrm{l})\end{array}$ & $\begin{array}{c}\text { Diluted sea } \\
\text { water(g/l) }\end{array}$ & $\begin{array}{c}\text { SSW } \\
\text { weight(g/l) }\end{array}$ & Manufacturer \\
\hline $\mathrm{NaCl}$ & 150 & 28 & 2.8 & 2.1 & Merck \\
\hline $\mathrm{CaCl}_{2} .6 \mathrm{H}_{2} \mathrm{O}$ & 49.5 & 1.38 & 0.138 & ---------- & Merck \\
\hline $\mathrm{NaHCO} 3$ & 0.66 & 0.1 & 0.01 & 0.0025 & Merck \\
\hline $\mathrm{KCl}$ & 0 & 0.8 & 0.08 & 1.45 & Merck \\
\hline $\mathrm{MgCl}_{2} .6 \mathrm{H}_{2} \mathrm{O}$ & 14.5 & 5.5 & 0.55 & --------- & Merck \\
\hline $\mathrm{Na}_{2} \mathrm{SO}_{4}$ & 0.403 & 4.4 & 0.44 & 0.44 & Merck
\end{tabular}

\subsubsection{Other materials.}

The $\mathrm{SiO}_{2}$ nanoparticles were used had an average particle size of about $30 \mathrm{~nm}$. We used stearic acid (with molar mass $248.48 \mathrm{~g} / \mathrm{mol}$ and density $941 \mathrm{~kg} / \mathrm{m}^{3}$ ) and normal heptane (with 
molar mass $100.21 \mathrm{~g} / \mathrm{mol}$ and density $684 \mathrm{~kg} / \mathrm{m}^{3}$ ) for oil wetting thin sections and kerosene were used to drop below the thin section in the presence of SSW.

\subsection{Methods.}

\subsubsection{Oil wetting procedure.}

The artificially plugs (mineralogical characteristics of the plugs are given in Table 1) were converted to thin sections with a thickness of $3 \mathrm{~mm}$ and a diameter of $25 \mathrm{~mm}$. Thin sections that had a smoother surface and more equal weight were selected for the experiments. Of the ten thin sections, two were considered as basal thin sections to compare the amount of sand produced without wettability alteration.

For wettability alteration, an equal volume of normal heptane was poured into four containers and prepared solution with concentrations of 0.005, 0.01, 0.02 and 0.03 Molar stearic acid in each container. Two thin sections were immersed in each container, one thin section for investigating the effect of wettability on sand production in SSW, and another one for investigating the effect of wettability on sand production in Nano-fluid. Then, the containers were placed in the reservoir temperature simulator for 72 hours at $65^{\circ} \mathrm{C}$ for the effect of stearic acid on the rock surface.

The normal heptane solution with different molars of stearic acid was made to oil wetting the thin sections at the different intensity of wettability. Stearic acid was used because the fatty acids in real oil and stearic acid are common and both can change the wettability of the rock surface.

\subsubsection{Nanofluid preparation.}

Copper, zinc, titanium, aluminum, and silica oxides nanoparticles were available for testing. Copper, titanium, aluminum and zinc oxides were difficult to stable in water and required surfactant and polymer to be stable and were not economical to use. There were two reasons for choosing silica nanoparticles: 1- Easy stability and no need for additives. 2- The same composition of silica nanoparticles with sandstone. Silica nanoparticles were selected due to these two reasons, which are economical to use.

Form the mentioned reasons and previous studies, concentrations of 500 and $1000 \mathrm{ppm}$ were considered for the preparation of Nanofluid. 1000cc of SSW were made according to Table 3 for the preparation of Nanofluid. 0.5 And $0.25 \mathrm{~g}$ of $\mathrm{SiO}_{2}$ nanoparticles were measured with a digital weighing accuracy of $0.1 \mathrm{mg}$ and placed in two containers. And in each container, $500 \mathrm{cc}$ of soft water was poured. It was placed on a magnetic stirrer for 30 minutes and sonicated for one hour. For stability evaluation visual and zeta potential tests were used.

\subsubsection{Contact angle and sand production measurement.}

To measure the thin sections wettability, (eight thin sections that were oil wetted in different molar of stearic acid and two Base thin sections), a contact angle setup was made, In this setup, two-fluid were used: kerosene (to drop) and brine.

Thin sections weight measurement and capture contact angle photos took 120 hours. To measure the weight of the thin sections, First, placed them at room temperature for 24 hours and then at $65^{\circ} \mathrm{C}$ for two hours to complete drying. On the initial day of the experiments, 500 cc of SSW were placed in the contact angle setup. To measure the contact angle, all ten thin 
sections were placed in the contact angle setup respectively, and ten images considered as initial day images. After measuring the weight and capturing the images of each thin section, $50 \mathrm{cc}$ of SSW were placed in five containers and $50 \mathrm{cc}$ of Nanofluid were placed in five other containers. Then each thin section according to its specification (meaning the specificity of the intensity of wettability created by stearic acid) was placed in its container and isolated with aluminum foil and kept in the reservoir temperature simulator for $24 \mathrm{~h}$. After 24 hours, the thin sections were removed from the containers and completely dried. Then their weights were measured and contact angle images were captured by the contact angle setup. This process was performed for 120 hours every 24 hours. In the end, by reducing the weight of thin sections on the initial day and fifth day, the amount of sand produced in different wettability was obtained. Digimizer software was used to measure the contact angle of images. Interesting results were obtained by determining the contact angle and weight of each thin section daily and comparing them with each other and investigate the effect of wettability on sand production per day.

\section{Results and Discussion}

Reservoir wettability usually shifts to oil wetting, because a very long time have been exposed to oil. In this project to simulate the actual reservoir conditions the thin sections oil wetted by stearic acid. The most important reason for using smart water was to increase oil recovery. Various mechanisms have been cited to increase oil recovery by smart water [24] [26]. Wettability alteration from oil-wet to water-wet around the wells results in faster oil production, increased oil production in the first two years of operation, and impedes water production [29] [30]. For wettability alteration, the water that is used must have much less salinity than the formation water to be able to shock to the reservoir [31] [32]. Nanoparticles can increase the oil recovery, increase the rock strength and changes the reservoir wettability to water wetting, so it is economical to use them [33-36].

\subsection{Wettability alteration and sand production in SSW.}

Sandstones usually contain large amounts of clay, when they were exposed to low saline water wettability alteration occurred. Dual-layer expansion, $\mathrm{pH}$ effect, salt in and salt out effect are factors that change the wettability by low salinity water. With these changes, sandstones move from oil-wet to water-wet and water adheres to the rock surface and oil can move freely [37-40] [24] [29]. In this part of the experiments, five thin sections (Base, 0.005, $0.01,0.02,0.03$ ) were placed in SSW. The composition of the thin sections was clay free and when they were exposed to SSW, gradually electrical charge of rock surface changes and it does wettability alteration. The thin sections become more water-wetted during 120-hours that they were in contact with the SSW.

After oil wetting and drying the thin sections, the initial weight of each of the five thin sections to be tested in the SSW was measured. The weight of all five thin sections is shown in Table 4.

Table 4. The initial weight of thin sections for SSW experiments.

\begin{tabular}{l|l|l|l|l|l} 
Molars of S.A & Base & $0.005 \mathrm{M}$ & $0.01 \mathrm{M}$ & $0.02 \mathrm{M}$ & $0.03 \mathrm{M}$ \\
\hline Weight $(\mathrm{g})$ & 8.12 & 8.02 & 8.2 & 7.96 & 8.14
\end{tabular}


In Figure 2, two examples of images captured by the Contact Angle Set up are visible. Fig. 2-a shows the initial day of the Base thin section and its contact angle was 95.2 degrees, Fig. 2-b shows the initial day of $0.005 \mathrm{M}$ thin section and its contact angle was 100.79 degrees.

In SSW for all thin sections (Base, 0.005M, 0.01M, 0.02M, and 0.03M) such as Fig. 2, for a total of 120 hours, 30 images were captured. By placing the thin sections in SSW, there were changes in the surface of the rock that became more and more water wetted and their contact angle were reduced every day. Fig. 2 shows the captured images and the amount of contact angle in SSW.

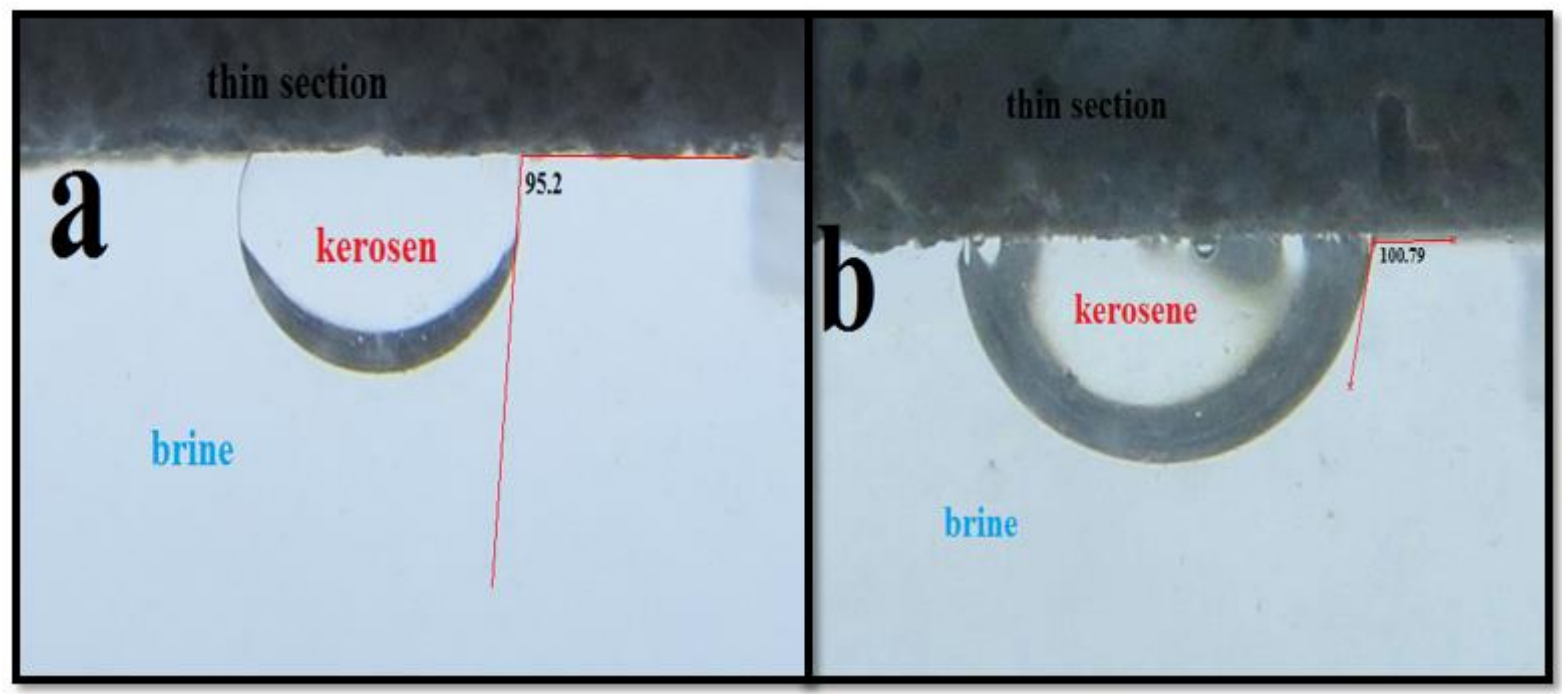

Figure 2. a) contact angle of base thin section b) contact angle of $0.005 \mathrm{M}$ thin section.

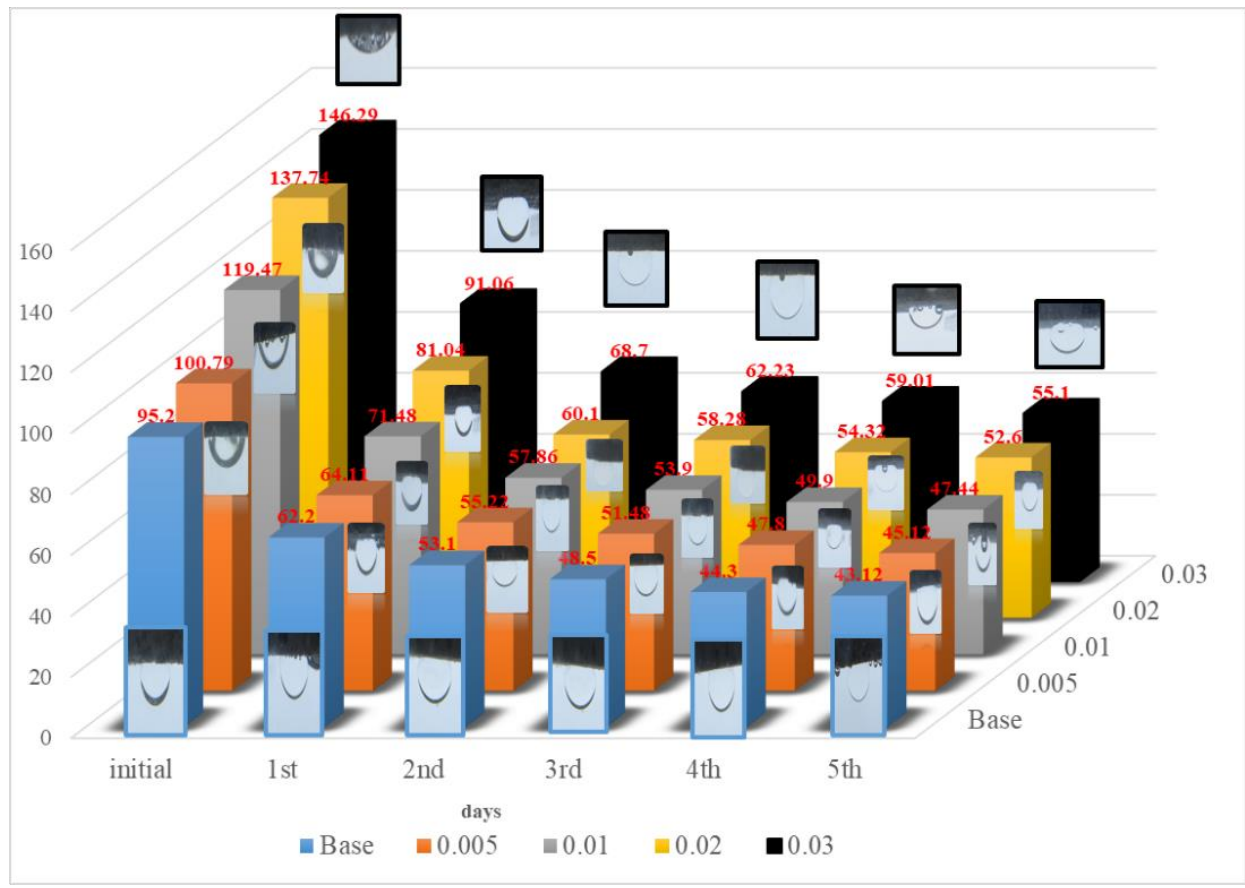

Figure 3. Contact angle measurement in SSW.

Disjoining pressure between the fatty acids and the surface of the thin section increased with the expansion of the double layer and increase in van der Waals force after immersion of the thin sections in the SSW, and the surface of the rock becomes ready to accept the polar water molecules. Since monovalent ions have more expansion in the double layer than divalent ions [41] when the thin sections were in the SSW, the double layer expands further and the 
disjoining pressure increases, resulting in a faster wettability alteration than the smart hard water. In Fig. 3, the Base thin section had the lowest contact angle on the initial day and the thin section that oil wetted with 0.03 molar stearic acid has the highest contact angle (strongest oil-wet). In Fig.3 all thin sections (Base and 0.005, 0.01, 0.02 and 0.03) had the greatest decrease in contact angle in the first $24 \mathrm{~h}$ and the downward trend continued with less slope in the following days.

For each contact angle one weight was measured, Figure 4 shows the daily weight of the thin sections. Comparison of Fig. 3 and Fig. 4 shows the effect of wettability on sand production.

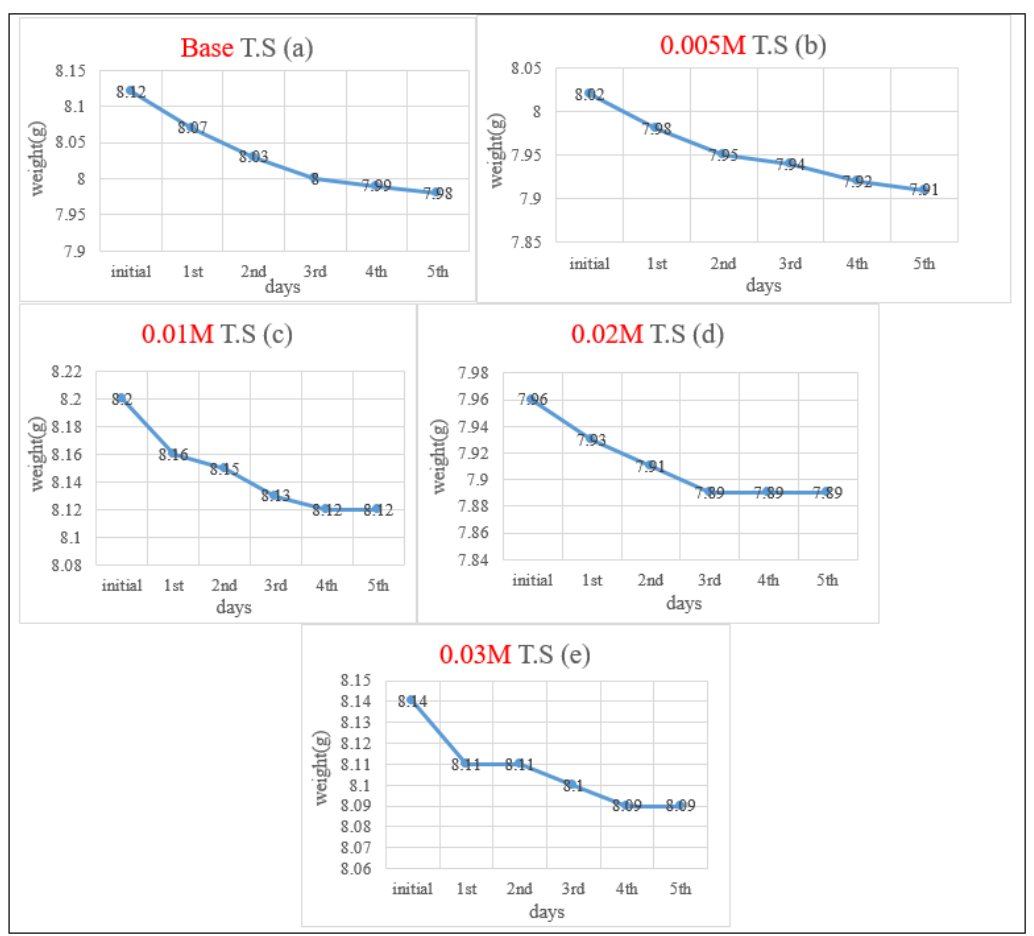

Figure 4. Sand production in SSW in different wettability.

In the base thin section (Fig. 3 and Fig.4-a), since it has a nearly neutral wettability, the SSW adheres to the rock surface much more easily and surrounds the rock grains. During the first 24 hours of testing, the most reactions occur and the highest sand production was observed. The amount of sand production was $1.724 \%$ of the total rock. The reason for very high sand production in this thin section was the faster surrounding the sand grains by water, which reduces the rock strength and, as there is no barrier (like Nano) we see some sand production daily. In this thin section, the contact angle is changed from 95.2 to 43.12 degrees within 120 hours, and $0.14 \mathrm{~g}$ of the thin section was produced.

In the thin sections $0.005 \mathrm{M}, 0.01 \mathrm{M}$ and $0.02 \mathrm{M}$ (Fig. 3 and Fig.4-b, c, d) produced $1.372 \%, 0.976 \%, 0.879 \%$ of the total rock, respectively. In these thin sections, because they were oil wetted, more time is needed to increase the disjoining pressure, which is why less sand was produced during the same time as the Base thin section.

The 0.03 molar thin section (Fig. 3 and Fig.4-e) was strong oil wetted, so it is very difficult for water to surround the rock grains because of the low disjoining pressure between the rock and the fatty acids. In the first 24 hours, most reactions occur and the amount of sand production was high. In this thin section, the contact angle decreased from 146.29 to 51.2 and 
produced $0.614 \%$ of the total rock. If testing continues in the next few days (more than 120 hours), it is likely that the effect of oil wetted wettability will disappear after some time.

\subsection{Wettability alteration and sand production in Nanofluid.}

The effect of rock wettability on sand production in SSW was investigated in the previous section. But in this section, we examine the effect of wettability on sand production in the presence of $\mathrm{SiO}_{2}$ Nanoparticles. The use of Nanoparticles in the injected water to the reservoir can increase the recovery factor by more than 50\% [15] [42-44] as well as reduce the viscosity of heavy oil [45]. The most common nanoparticle for this work is $\mathrm{SiO}_{2}$ [13] [45] [46]. Various studies have been performed on nanoparticles to prevent the fine migration, which has had excellent results, also nanoparticles have very little formation damage [19]. Studies on nanoparticles to prevent sand production have been performed that showed Nano can prevent sand production [16] [19] [20].

Both Nanofluids that made (500 ppm and $1000 \mathrm{ppm}$ ) were visually stable in SSW. According to previous studies, 120 hours were considered for the complete comparison of the produced sand. Therefore, the Nanofluid must be stable at this time and be able to affect on the rock surface. The zeta potential test was used to determine which Nanofluids were more stable and, the results are given in Table 5.

Table 5. Result of zeta potential test.

\begin{tabular}{c|c|c|c} 
Nano fluid & Zeta potential $(\mathrm{mV})$ & Average diameter $(\mathrm{nm})$ & Stability quality \\
\hline $1000 \mathrm{ppm}$ & -27 & 199 & Very good \\
\hline $500 \mathrm{ppm}$ & -21 & 298 & good
\end{tabular}

Nanofluid with a concentration of $1000 \mathrm{ppm}$ has higher zeta potential and lower average particle diameter, both of them indicate good dispersion of Nano in SSW and the concentration of 1000 ppm was chosen as the optimal Nanofluid for testing.

In this part of the experiment, the dry weight of thin sections was measured (Table 6) and the experiment was performed for 120 hours in SSW with Nano and the contact angle was measured for each weight.

Table 6. The initial weight of thin sections for Nano fluid experiment.

\begin{tabular}{l|l|l|l|l|l} 
Molars of S.A & Base & $0.005 \mathrm{M}$ & $0.01 \mathrm{M}$ & $0.02 \mathrm{M}$ & $0.03 \mathrm{M}$ \\
\hline Weight $(\mathrm{g})$ & 7.81 & 7.68 & 7.9 & 7.73 & 7.77
\end{tabular}
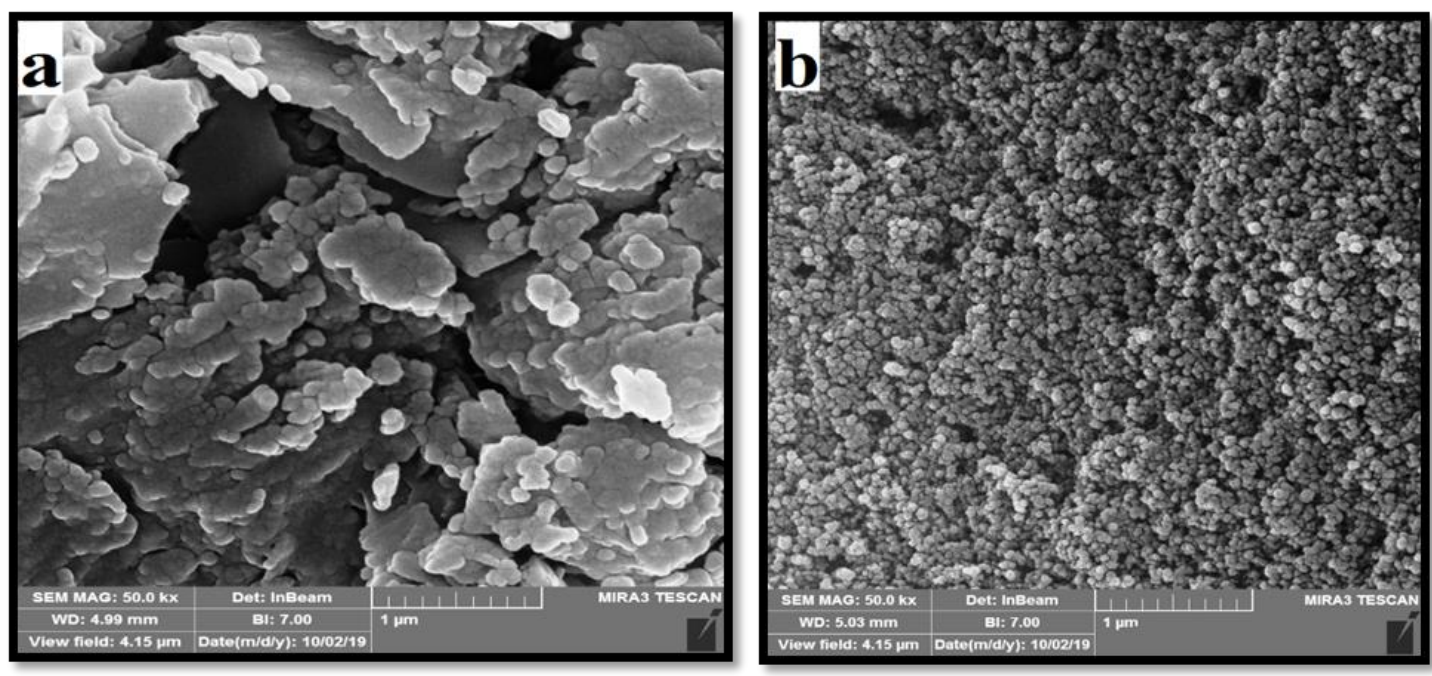

Figure 5. Rock surface, a) before submerging in the Nanofluid. b) After submerging in the Nanofluid. 
Thin sections should be coated by Nanoparticles. Scanning electron microscopy was used to ensure that the surface of the thin sections was coated with $1000 \mathrm{ppm} \mathrm{SiO}_{2} \mathrm{Nanofluid}$ At first, a photo was taken from the thin section surface (Fig. 5-a), then the thin section was immersed in Nanofluid for 24 hours, and another photo was captured (Fig. 5-b). By comparing these two photos, it was observed that the Nano covered the surface of the rock very well within 24 hours, and thus the Nano was expected to be able to accelerate the changing of rock wettability and reduce sand production.

By immersing thin sections in Nanofluids and capturing images every 24 hours by the contact angle setup for $120 \mathrm{~h}$, the wettability alteration of the thin sections was measured. Images and the amount of contact angle are given in Figure 6. The thin sections which were immersed in the Nanofluid, their wettability changed for two reasons: 1- SSW performance, 2Silica nanoparticle performance. As mentioned, smart water changes wettability by increasing the volume of the double layer. When the rock was placed in the Nanofluid, the Nanoparticles after several hours by creating Nano textures on the surface of the rock, Make the surface of the rock more water wetted. By comparing the wettability alteration in Fig. 3 and Fig. 6, it can be easily understood that the Nanofluid causes more wettability alteration.

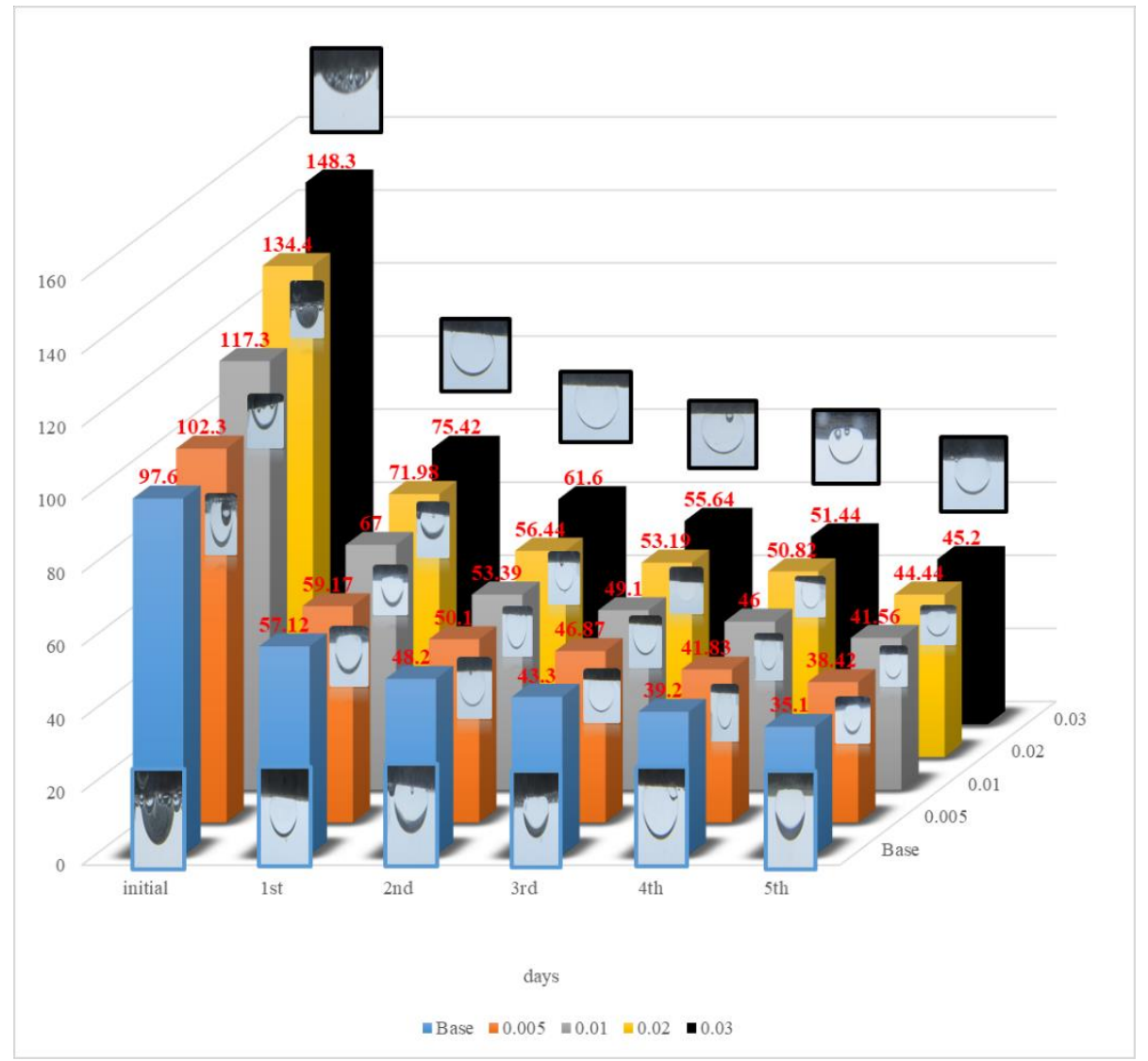

Figure 6. Contact angle measurement in SSW (Nano fluid).

Figure 7 shows the daily weight of the Thin Sections. Silica nanoparticles were easily seated on the rock surface and increase the adhesion between the grains due to chemical changes on the rock surface. In Figure 7, each diagram corresponds to thin sections that having a different contact angle value.

As shown in Fig.7-a, the amount of sand produced in the Base thin section was high on the first day. After 24 hours, due to the effect of silica nanoparticles, the amount of sand production decreased sharply. In this thin section, the contact angle has reached from 97.6 to 
35.1 degrees (Fig.6), which was lower than the change in wettability in the non-Nano state (Fig.3: 95.2 to 43.12), that was due to the formation of Nano textures on the rock surface. This thin section produces $1.152 \%$ of the total rock, which was much lower than the non-Nano-state (Fig.4).

In the thin sections $0.005,0.01,0.02$, which was oil wetted, according to Fig.7-b, c, d the amount of sand production was 0.781 and 0.632 and $0.517 \%$ of the total rock, respectively. Only the wettability (Fig.6) has changed in these three thin sections, but different sand production was observed. It was indicating the effect of wettability on sand production.

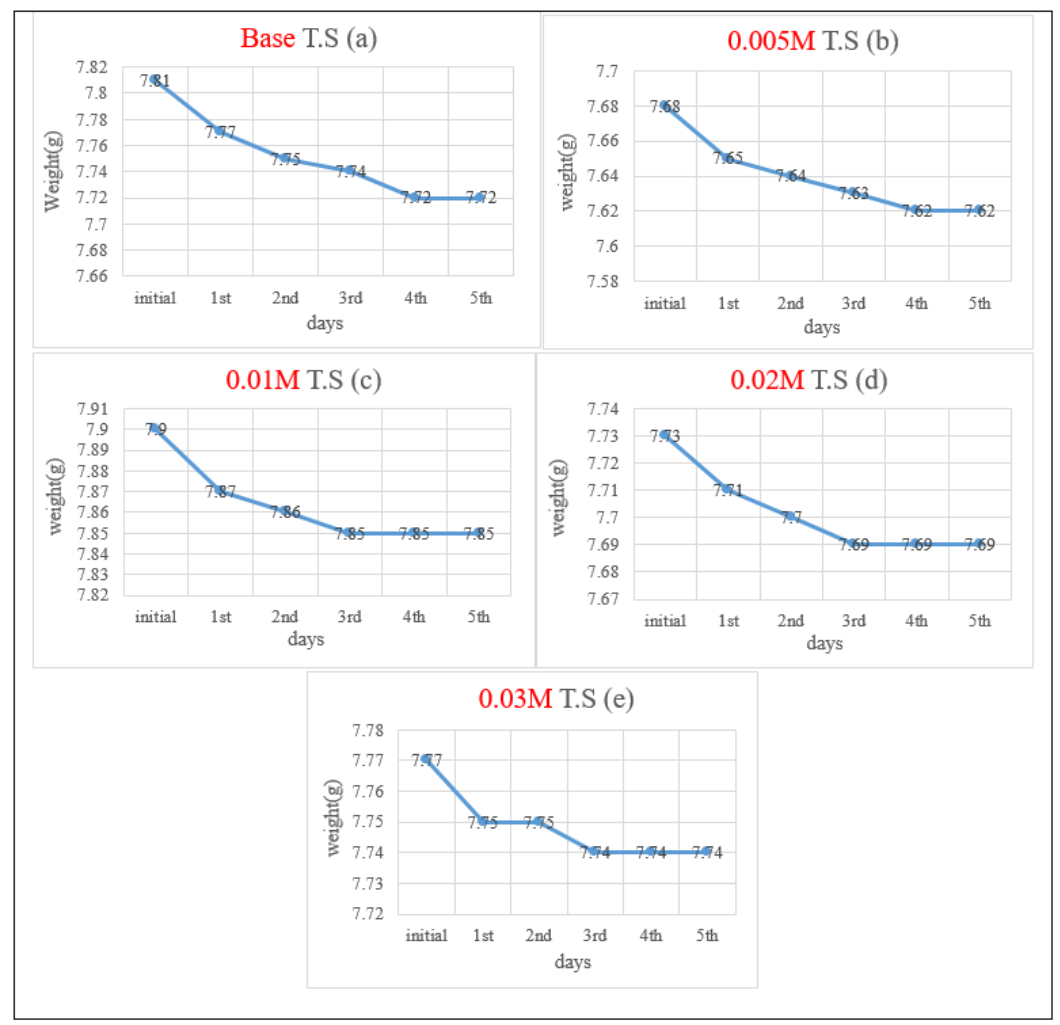

Figure 7. Sand production in SSW with Nano (Nanofluid) in different wettability.

At $0.03 \mathrm{M}$ thin section (Fig.6 and Fig.7-e), which was strongly oil wetted, SSW and silica nanoparticles change the wettability from 148.3 to 45.2 , but the change of wettability does not produce much sand. This thin section had less sand production than the other thin sections, the reason for the low sand production in this tin section was the effect of silica nanoparticles, and the coating of the rock surface by fatty acids.

\subsection{Comparison between wettability alteration effects.}

SSW (with double layer expansion) and nanoparticles (with Nano texture creation) change the wettability. As the wettability shifts to water wetting, the rock grains were surrounded by water, causing the static equilibrium disruption and sand produced. When the oil wetted rock comes in contact with SSW, the disjoining pressure was initially low and the water wants to increase the disjoining pressure. In strongly oil wetted rock, water needs more time to increase disjoining pressure. If there are no additives in the water, over time, the water will surround the rock grains and disturb the equilibrium of the rock and sand produced. But if additives (like Nano) were present in water, the Nano will be trapped between the rock grains during the time that water needs to changes the wettability, preventing further sand production. 
As can be seen in Fig.8, in all cases the $\mathrm{SiO}_{2}$ decreased the sand production and averaged more than $40 \%$ inhibition of sand production. By increasing in oil-wetting of the rock, the amount of sand production was reduced. In this project utilized SSW and Nano, which had the following advantages:

a. Low salinity water due to different compositions with the formation of water will change the wettability and disturb the static equilibrium of the reservoir.

b. Smart water due to having more monovalent ions (than smart hard water in the same salinity) causes more expansion of the double layer and accelerates the wettability alteration.

c. Silica nanoparticles change the wettability and increase the oil recovery factor and also impede sand production, however, its use has economic benefits.

d. When rock wettability changes, the sand begins to produce. By increasing the intensity of rock oil wetting, the static equilibrium lasts longer and less sand was produced at the same time. If there is Nano, The delay in wettability alteration (equilibrium disruption) causes the Nano to sit on the rock and prevent sand production.

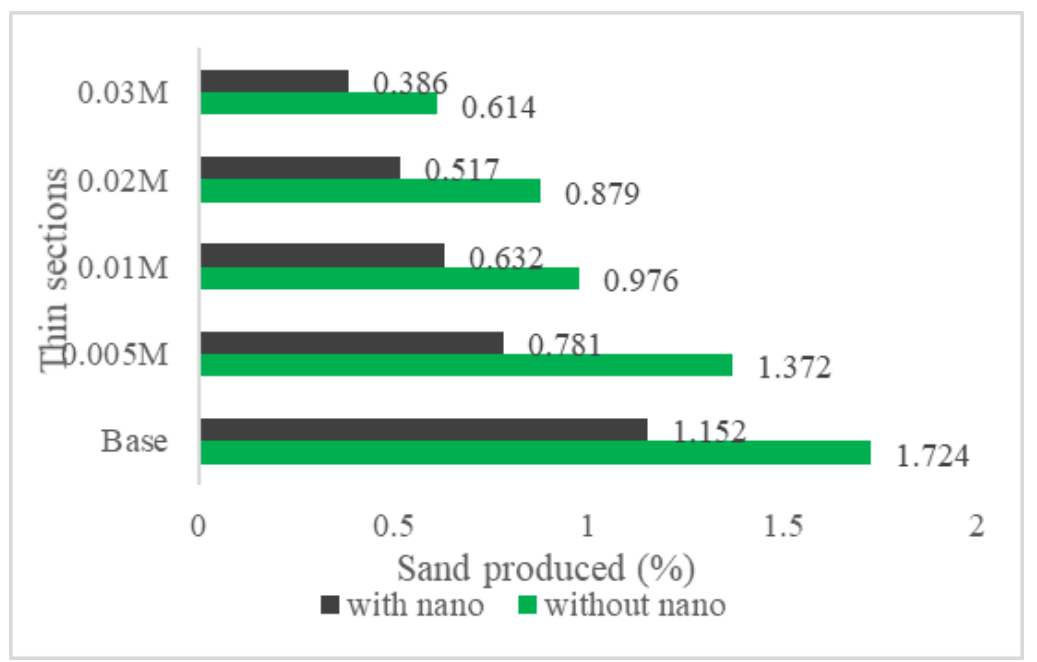

Figure 8. Sand production of different thin sections in the presence and absence Nano.

\section{Conclusions}

Wettability alteration occurs by putting oil wetted rocks in SSW, and with increasing rock oil wetting, less sand production was observed at the same time.

The most chemical reactions at the rock surface occur at the beginning of the experiment. In the presence and absence of Nanoparticles, in the beginning, the highest sand production was observed. But by over time, the slope of the sand production diagram in the presence of Nano tends to zero, vice versa the absence of Nano.

Zeta potential test showed that the stability in SSW had no significant relationship with the concentration of Nano. In the presence of $\mathrm{SiO}_{2}$ due to the formation of Nano textures on the rock surface, the wettability alteration was faster than the absence of $\mathrm{SiO}_{2}$ nanoparticles.

The minimum amount of sand production was observed if the rock was strong oil wetted and using Nano. In the presence and absence of $\mathrm{SiO}_{2}$ Nanoparticles, the amount of sand production decreases as the wettability shifts to oil wetting.

\section{Funding}

This research received no external funding. 


\section{Acknowledgments}

This research has no acknowledgments.

\section{Conflicts of Interest}

The authors declare no conflict of interest.

\section{References}

1. Adeyanju, O.A.; Oyekunle, L.O. Experimental studies of sand production from the unconsolidated sandstone Niger-delta petroleum reservoir. SPE-151008-MS 2011, 18, https://doi.org/10.2118/151008-MS.

2. Talaghat, M.; Esmaeilzadeh, F.; Mowla, D. Sand production control by chemical consolidation. Journal of Petroleum Science and Engineering 2009, 67, 34-40, https://doi.org/10.1016/j.petrol.2009.02.005.

3. Zhang, F.; Feng, D. Hydraulic fracturing simulation test and fracture propagation analysis of large-scale coal rock under true triaxial conditions. Rock Soil Mech 2019, 40, 1890-1897.

4. Anderson, W.G. Wettability Literature Survey- Part 1: Rock/Oil/Brine Interactions and the Effects of Core Handling on Wettability. SPE-13932-PA 1986, 38, 1125-1144, https://doi.org/10.2118/13932-PA.

5. Salathiel, R. Oil recovery by surface film drainage in mixed-wettability rocks. J Petrol Techno 1973, 25, 11216-24, https://doi.org/10.2118/4104-PA.

6. Rezaei Doust, A.; Puntervold, T.; Austad, T. A Discussion of Low Salinity EOR Potential for North Sea Sandstone Field. SPE-134459-MS 2010, 12, https://doi.org/10.2118/134459-MS.

7. Nasralla, R.A.; Nasr-El-Din, H.A. Impact of cation type and concentration in injected brine on oil recovery in sandstone reservoirs. Journal of Petroleum Science and Engineering 2014, 122, 384-395, https://doi.org/10.1016/j.petrol.2014.07.038

8. Ali, J.A.; Kolo, K.; Manshad, A.K.; Mohammadi, A.H. Recent advances in application of nanotechnology in chemical enhanced oil recovery: Effects of nanoparticles on wettability alteration, interfacial tension reduction, and flooding. Egyptian Journal of Petroleum 2018, 27, 1371-1383, https://doi.org/10.1016/j.ejpe.2018.09.006

9. Zhang, T.; Davidson, A.; Bryant, S.L.; Huh, C. Nanoparticle-stabilized emulsions for applications in Enhanced Oil Recovery. Improved Oil Recovery Symposium. SPE-129885 2010, 18, https://doi.org/10.2118/129885-MS.

10. Kelessidis, V.C.; Nasr-El-Din, H.A.; Mahmoud, O.; Vryzas, Z. Development and testing of novel drilling fluids using $\mathrm{Fe} 2 \mathrm{O} 3$ and $\mathrm{SiO} 2$ nanoparticles for enhanced drilling operations. International Petroleum Technology Conference. IPTC-18381-MS, 2015, 68, https://doi.org/10.2523/IPTC-18381-MS.

11. Soleimani, H.; Baig, M.K.; Yahya, N.; Khodapanah, L.; Sabet, M.; Demiral, B.M.R.; Burda, M. Synthesis of $\mathrm{ZnO}$ nanoparticles for oil-water interfacial tension reduction in enhanced oil recovery. Applied Physics A 2018, 124, 128, https://doi.org/10.1007/s00339-017-1510-4.

12. Kuznetsov, O.V.; Suresh, R.; Agrawal, D.K.; Mazyar, O.A.; Feng, X.; Behles, J.A.; Khabashesku, V.N. Enhancing bitumen flotation with colloidal nanoparticles. Offshore Technology Conference 2015, https://doi.org/10.4043/26083-MS.

13. Qiu, F. The potential applications in heavy oil EOR with the nanoparticle and surfactant stabilized solventbased emulsion. International Petroleum Conference 2010, https://doi.org/10.2118/134613-MS.

14. Kim, I.; Worthen, A.J; Lotfollahi M; Johnston K.P; DiCarlo D.A; Huh C. Nanoparticle-stabilized emulsions for improved mobility control for adverse-mobility waterflooding. USA. SPE-179644-MS 2016, 10, https://doi.org/10.2118/179644-MS.

15. Punvichai, T.; Pioch, D. Co-valorization of agro-industry by-products: effect of citrus oil on the quality of soap derived from palm fatty acid distillate and spent bleaching clay. Letters in Applied NanoBioScience 2019, 8, https://doi.org/10.33263/LIANBS83.571575.

16. Mishra, S.; Ojha, K. Nanoparticle induced chemical system for consolidating loosely bound sand formations in oil fields. Journal of Petroleum Science and Engineering 2016, 147, 15-23, https://doi.org/10.1016/j.petrol.2016.05.005

17. Alhuraishawy, A.K.; Bai, B.; Wei, M.; Geng, J.; Pu, J. Mineral dissolution and fine migration effect on oil recovery factor by low-salinity water flooding in low-permeability sandstone reservoir. Fuel 2018, 220, 898907, https://doi.org/10.1016/j.fuel.2018.02.016.

18. Huang, T.; Crews, J.B.; Willingham, J.R. Nanoparticles for formation fines fixation and improving performance of surfactant structure. IPTC-12414-MS 2003, https://doi.org/10.2523/IPTC-12414-MS.

19. Pathak, J.; Sonker, A.S.; Singh, V.; Kumar, D.; Sinha, R.P. Synthesis of silver nanoparticles from extracts of Scytonema geitleri HKAR-12 and their in vitro antibacterial and antitumor potentials. Letters in Applied NanoBioScience 2019, 8, https://doi.org/10.33263/LIANBS83.576585 
20. Tan, P.; Jin, Y.; Yuan, L.; Xiong, Z.Y.; Hou, B.; Chen, M.; Wan, L.M. Understanding hydraulic fracture propagation behavior in tight sandstone-coal interbedded formations: an experimental investigation. Petroleum Science 2019, 16, 148-160, https://doi.org/10.1007/s12182-018-0297-z.

21. Al-Anssari, S.; Arif, M.; Wang, S.; Barifcani, A.; Lebedev, M.; Iglauer, S. CO2 geo-storage capacity enhancement via nanofluid priming. International Journal of Greenhouse Gas Control 2017, 63, 20-25, https://doi.org/10.2118/192964-MS

22. Lager, A.; Webb, K.J.; Collins, I.R.; Richmond, D.M. LoSal enhanced oil recovery: Evidence of enhanced oil recovery at the reservoir scale. SPE-113976-MS 2008, 10, https://doi.org/10.2118/113976-MS

23. Ding, H.; Rahman, S. Experimental and theoretical study of wettability alteration during low salinity water flooding-an state of the art review. Colloids and Surfaces A: Physicochemical and Engineering Aspects 2017, 520, 622-639, https://doi.org/10.1016/j.colsurfa.2017.02.006

24. Alhuraishawy, A.K.; Bai, B.; Wei, M.; Geng, J.; Pu, J. Mineral dissolution and fine migration effect on oil recovery factor by low-salinity water flooding in low-permeability sandstone reservoir. Fuel 2018, 220, 898907, https://doi.org/10.1016/j.fuel.2018.02.016.

25. Mohan, K.K.; Vaidya, R.N.; Reed, M.G.; Fogler, H.S. Water sensitivity of sandstones containing swelling and non-swelling clays. Colloids and Surfaces A: Physicochemical and Engineering Aspects 1993, 73, 237254, https://doi.org/10.1016/0927-7757(93)80019-B.

26. Rezaei Doust, A.; Puntervold, T.; Austad, T. Chemical Verification of the EOR Mechanism by Using Low Saline/Smart Water in Sandstone. Energy \& Fuels 2011, 25, 2151-2162, https://doi.org/10.1021/ef200215y.

27. Mohammadi, H.; Jerauld, G. Mechanistic modeling of the benefit of combining polymer with low salinity water for enhanced oil recovery. SPE 153161-MS 2012, 11, https://doi.org/10.2118/153161-MS.

28. Henthorne, L.; Pope, G.A.; Weerasooriya, U.; Llano, V. Impact of Water Softening on Chemical Enhanced Oil Recovery Project Economics. SPE-169165 MS 2014, https://doi.org/10.2118/169165-MS.

29. R Daniely Ferreira; Emerson Rodrigues; Marco Antonio Utrera Martines. Synthesis and characterization of magnetic nanoparticles of cobalt ferrite coated with silica. Biointerface Research in Applied Chemistry 2019. https://doi.org/10.33263/BRIAC101.908913.

30. Martínez-Jiménez, M.; Saint-Martin, H. A Four-Site Molecular Model for Simulations of Liquid Methanol and Water-Methanol Mixtures: MeOH-4P. Journal of Chemical Theory and Computation 2018, 14, 25262537, https://doi.org/10.1021/acs.jctc.7b01265.

31. Zhang, P.; Tweheyo, M.T.; Austad, T. Wettability alteration and improved oil recovery by spontaneous imbibition of seawater into chalk: Impact of the potential determining ions $\mathrm{Ca} 2+, \mathrm{Mg} 2+$, and $\mathrm{SO} 42-$. Colloids and Surfaces A: Physicochemical and Engineering Aspects 2007, 301, 199-208, https://doi.org/10.1016/j.colsurfa.2006.12.058.

32. Arab, D.; Pourafshary, P. Nanoparticles-assisted surface charge modification of the porous medium to treat colloidal particles migration induced by low salinity water flooding. Colloids and Surfaces A: Physicochemical and Engineering Aspects 2013, 436, 803-814, https://doi.org/10.1016/j.colsurfa.2013.08.022.

33. Tamilvanan, S.; Gill, S. Candidiasis management: current status of allopathic drugs and utility of corianderbased oil-less emulsions. Letters in Applied NanoBioScience 2019, 8, https://doi.org/10.33263/LIANBS83.586590.

34. Najafpour, M.M.; Amini, E.; Madadkhani, S. Nano-sized manganese oxide coated sea sand: A new wateroxidizing catalyst. International Journal of Hydrogen Energy 2016, 41, 22866-22875, https://doi.org/10.1016/j.ijhydene.2016.08.030.

35. Ju, B.; Fan, T.; Ma, M. Enhanced oil recovery by flooding with hydrophilic nanoparticles. China Particuology 2006, 4, 41-46, https://doi.org/10.1016/S1672-2515(07)60232-2.

36. Miranda, C.R.; De Lara, L.S.; Tonetto, B.C. Stability and mobility of functionalized silica nanoparticles for enhanced oil recovery application. Soc. Pet. Eng. SPE 157033-MS 2012, https://doi.org/10.2118/157033MS.

37. RezaeiDoust, A.; Puntervold, T.; Strand, S.; Austad, T. Smart Water as Wettability Modifier in Carbonate and Sandstone: A Discussion of Similarities/Differences in the Chemical Mechanisms. Energy \& Fuels 2009, 23, 4479-4485, https://doi.org/10.1021/ef900185q.

38. Muggeridge, A.; Cockin, A.; Webb, K.; Frampton, H.; Collins, I.; Moulds, T.; Salino, P. Recovery rates, enhanced oil recovery and technological limits. Philos Trans A Math Phys Eng Sci 2013, 372, 2012032020120320, https://dx.doi.org/10.1098\%2Frsta.2012.0320.

39. Wang, H.; Sharma, M.M. The Role of Elasto-Plasticity in Cavity Shape and Sand Production in Oil and Gas Wells. SPE-187225-PA 2019, 24, 744-756, https://doi.org/10.2118/187225-PA.

40. Hosseinzade Khanamiri, H.; Baltzersen Enge, I.; Nourani, M.; Stensen, J.Å; Torsæter, O.; Hadia, N. EOR by Low Salinity Water and Surfactant at Low Concentration: Impact of Injection and in Situ Brine Composition. Energy \& Fuels 2016, 30, 2705-2713, https://doi.org/10.1021/acs.energyfuels.5b02899.

41. Mugele, F.; Bera, B.; Cavalli, A.; Siretanu, I.; Maestro, A.; Duits, M.; Cohen-Stuart, M.; van den Ende, D.; Stocker, I.; Collins, I. Ion adsorption-induced wetting transition in oil-water-mineral systems. Scientific Reports 2015, 5, https://doi.org/10.1021/ef1000908. 
42. Cheraghian, G.; Khalili Nezhad, S.S.; Kamari, M.; Hemmati, M.; Masihi, M.; Bazgir, S. Adsorption polymer on reservoir rock and role of the nanoparticles, clay and SiO2. International Nano Letters 2014, 4, 114-117, https://doi.org/10.1007/s40089-014-0114-7.

43. Mamonov, A.; Khan, M.A.I.; Puntervold, T.; Strand, S. Optimized alkalinity for EOR purpose in sandstone reservoir. SPE-192015-MS 2018, https://doi.org/10.2118/192015-MS.

44. Hou, B.; Zhang, R.; Chen, M.; Kao, J.; Liu, X. Investigation on acid fracturing treatment in limestone formation based on true tri-axial experiment. Fuel 2019, 235, 473-484, https://doi.org/10.1016/j.fuel.2018.08.057.

45. Z Elazab, H.A.; El-Idreesy,T.T. Optimization of the catalytic performance of $\mathrm{Pd} / \mathrm{Fe} 3 \mathrm{O} 4$ nanoparticles prepared via microwave-assisted synthesis for pharmaceutical and catalysis applications. Biointerface Research in Applied Chemistry 2018, https://doi.org/10.33263/BRIAC91.794799

46. Zeinijahromi, A.; Farajzadeh, R.; Bruining, J.; Bedrikovetsky, P. Effect of fines migration on oil-water relative permeability during two-phase flow in porous media. Fuel 2016, 176, 222-236, https://doi.org/10.1016/j.fuel.2016.02.066. 